\title{
Development and Assessment of Hot-Film Sensor Technique for the Multistage Turbomachinery Environment
}

\author{
J. PRATO, B. LAKSHMINARAYANA*, and N. SURYAVAMSHI \\ Center for Gas Turbines and Power, The Pennsylvania State University, 153-J Hammond Building, \\ University Park, PA 16802, USA
}

\begin{abstract}
The slanted hot-film technique has been successfully modified and adapted for flow measurement in the complex and hostile environment encountered in multistage turbomachinery. The sources of probe and prong vibrations and methods of eliminating them are discussed. The incorporation of compressibility corrections and improvements in calibration techniques developed are discussed. The procedure is validated against the data from a five-hole probe. Suggestions are made for improving the accuracy of measurement. The ensembleaveraged data is resolved into time average, blade periodic, blade aperiodic, and non-deterministic velocity components. This is used to model the turbomachinery flow field. The flow is found to be highly complex with appreciable secondary flow in the casing region, and large flow unsteadiness in the suction-casing corner region.
\end{abstract}

Keywords: Hot film sensor; Turbomachinery; Compressibility; Calibration

\section{INTRODUCTION}

The multistage turbomachinery has one of the most complex flow phenomena encountered in fluid dynamic practice. The flow field is compressible, three-dimensional, turbulent, and highly unsteady; and the flow encounters alternate rotating and stationary blade rows with substantial curvature and rotation effects. The blade and the annulus wall boundary layer development and their mixing in inter- and intra-blade row introduces large viscous losses

\footnotetext{
Received 27 February 2001; in final form 27 March 2001.

${ }^{*}$ Corresponding author. Te1.: 814865 5551, Fax: 814-865-7092. E-mail: b21@psu.edu
}

and flow deviation from the design conditions. The presence and interaction of secondary flow, leakage flow, blade boundary layers and wakes, end wall boundary layer growth, all of which are three-dimensional, makes it truly a challenging flow to measure, compute, and understand. These complexities are compounded in a multistage compressor due to the presence of several closely packed stages and high hub-to-tip ratio annulus. These complexities have eluded the designers and researchers, and very few attempts have been made to gain a good understanding of the flow in a multistage environment. The design of multistage compressors is still largely based on empirical correlations derived from single stage and cascade data.

A systematic and a building block approach is essential in understanding the various flow phenomena, and their relative order of magnitude and interaction effects. It is only through such an understanding that improvements can be made in performance, analysis, and design of blading and blade rows. Therefore, there is a need for a systematic study of the multistage turbomachinery flow field in order to develop a working knowledge of the unsteady, three-dimensional turbulent flow field, rotorstator interaction, tip clearance effects, annulus wall boundary layer growth, etc. In addition, major advances have been made in recent years to predict the flow field in single-stage and multistage turbomachinery using the full Navier-Stokes equations. Most of these techniques and codes have numerical dissipation, empirically based turbulence closure models. Validation experiments become very crucial in establishing confidence in these codes for ultimate use in design and analysis beyond the existing data bases. Acquisition of such data is one of the objectives of the present research program.

The unsteadiness in turbomachines has been generally categorized as being either "periodic" or "unresolved." Flow field fluctuations at discrete frequencies (e.g., blade passing frequency, shaft frequency, etc.) are termed 
"periodic" unsteadiness. "Unresolved" unsteadiness has been used as to include all flow-field fluctuations due to turbulence, vortex shedding and any other unsteadiness not correlated with the rotor speed. The passage-averaged equations of fluid motion include terms which account for the time-averaged effects of the unsteady flows. Designers have not been able to assess the importance of these unsteady terms due to a lack of experimental data.

Due to the complexities of the flow field, geometry, and high speed, very few attempts have been made to measure the flow field in such an environment. Limited studies include unsteady pressure measurement (Cherrett \& Bryce, 1992; Suryavamshi et al., 1997). The laser measurements are restricted to large scale- low speed machines (e.g., Stauter, 1992). In view of the narrow passages and the high hub-to-tip ratios, and closely packed blades, the laser doppler velocimeter measurement technique is not suitable due to inaccessibility of some of the regions in the passage. This leaves the conventional measurement techniques (hot-wire, hot-film, five-hole probe) as the only feasible techniques. The hot-wire/film measurement technique for simple turbomachinery configurations (low speed, single stage, large scale) have been successfully developed and used (e.g., Lakshminarayana, 1981, 1996; Inoue, 1986). Bruun (1995) provides a detailed description of the procedure, calibration techniques, error analysis, and literature survey relevant to the hot film and its application to turbomachinery flows.

A major objective of the research reported in this paper is to develop a hot-film anemometry technique for the multistage turbomachinery environment and to assess the feasibility and accuracy of measuring the threedimensional steady and unsteady components of velocity, including calibration techniques, and the incorporation of compressibility effects. The technique is used to derive a detailed understanding of steady and unsteady flow field in multistage turbomachinery and develop flow models.

\section{TEST FACILITY, INSTRUMENTATION AND DATA ACQUISITION SYSTEM}

The test compressor used in this study is a three-stage axial flow compressor consisting of an inlet guide vane row and three stages of rotor and cantilevered stator blading with a rotating hub. The general specifications of the compressor are listed in Table I. The outer annulus wall has a constant diameter of $0.6096 \mathrm{~m}$. The hub wall diameter varies from $0.5075 \mathrm{~m}$ at the inlet to $0.5232 \mathrm{~m}$ at the exit. The drive assembly is comprised of a $372 \mathrm{KW}$ induction motor (with a frequency controlled inverter) coupled to the compressor via a 1:1.67 ratio speed increaser gear box and a

TABLE I General specifications of test compressor

Number of Stages

Tip Diameter

Hub Diameter at inlet

Hub Diameter at exit

Blade Count (rotor 1,2,3)

Blade Count (stator 1,2,3)

Corrected Rotor Speed

Corrected Mass Flow

Overall Total Pressure Ratio

Mass-Averaged Peak Efficiency at $100 \%$

Corrected Speed (Torque Based)

Blade Tip Mach Number

Average Reynolds Number

Average Hub-Tip Ratio

Diffusion Factor (Avg.)

Average Stage Flow coefficient $\left(V_{z} / U_{t}\right)$

Reaction (avg.)

Space Chord Ratio (avg.)

Aspect Ratio (avg.)

Aspect Rotor Tip Clearance (dynamic)

3

$0.6096 \mathrm{~m}$

$0.5075 \mathrm{~m}$

$0.5232 \mathrm{~m}$

$70,72,74$

$71,73,75$

$5410 \mathrm{rpm}$

$8.609 \mathrm{~kg} / \mathrm{s}$

1.354

$90.65 \%$

0.5 $2.448 \times 10^{5}$

0.843

0.438

0.509

0.570

0.780

1.500

(1.368\% Span)

torque-meter. Further details of the compressor facility are given in Lakshminarayana (1994).

In order to acquire instantaneous pressure, velocity and turbulence data in an embedded stage, an area traverse mechanism was designed and built at The Pennsylvania State University. The area traverse mechanism shown in Figure 2 allows detailed area traversing of $11 / 2$ blade passages downstream of stator 2 (station 6), downstream of rotor 3 (station 7) and downstream of stator 3 (station 8). The traverse mechanism allows for tangential and radial traverses and probe rotation about its axis (3 degrees of freedom). The mechanism is enclosed in a sealed chamber (A) which is mounted on the compressor outer casing. The probe $(\mathrm{K})$ is encased in a teflon shoe $(\mathrm{F})$ which is traversed in a slot (E), which ensures a smooth interface between the probe and the casing wall $(\mathrm{G})$. The teflon shoes are designed to be at least three probe diameters wide on each side, to minimize local flow disturbances. The probes are traversed by stepper motors $(\mathrm{B}, \mathrm{C}$, and $\mathrm{H})$ driven by a computer. The stepper motors are of $0.10565 \mathrm{~kg} . \mathrm{m}$ torque and are controlled by a stepper motor controller. The stepper motor for the tangential traverse $(\mathrm{H})$ moves the chain driven sprocket, which moves the traverse gear (I) using the chain (J). Radial motion is achieved by the stepper motor (B) which moves the slide (D). Stepper motor $\mathrm{C}$ is utilized for rotating the probe about its own axis. Provisions are made for interfacing pneumatic and electrical lines through the side wall of chamber to provide both motion control and data acquisition. The area traverse mechanism can be driven by either a software driver (Q-Basic language) interfaced with the data acquisition software to acquire the pressure data or by a command file format to acquire the data with the data acquisition system. The 


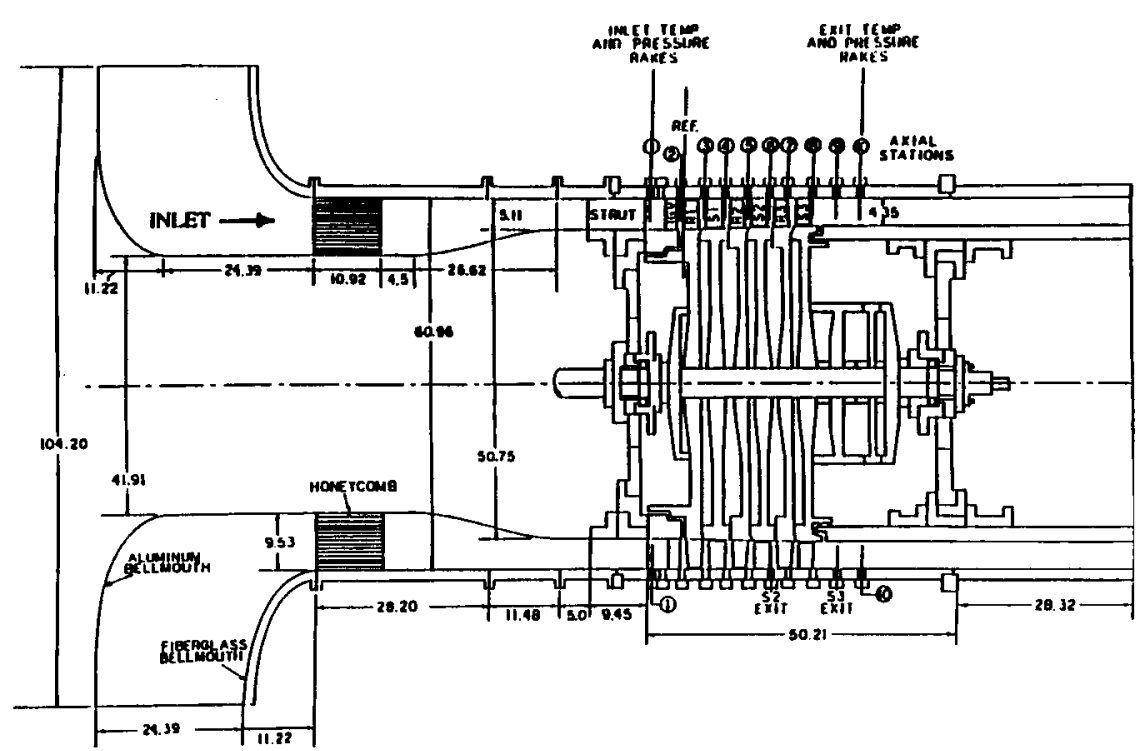

FIGURE 1 Schematic drawing of compressor flow path and measurement locations (all dimensions are in $\mathrm{cms}$ ).

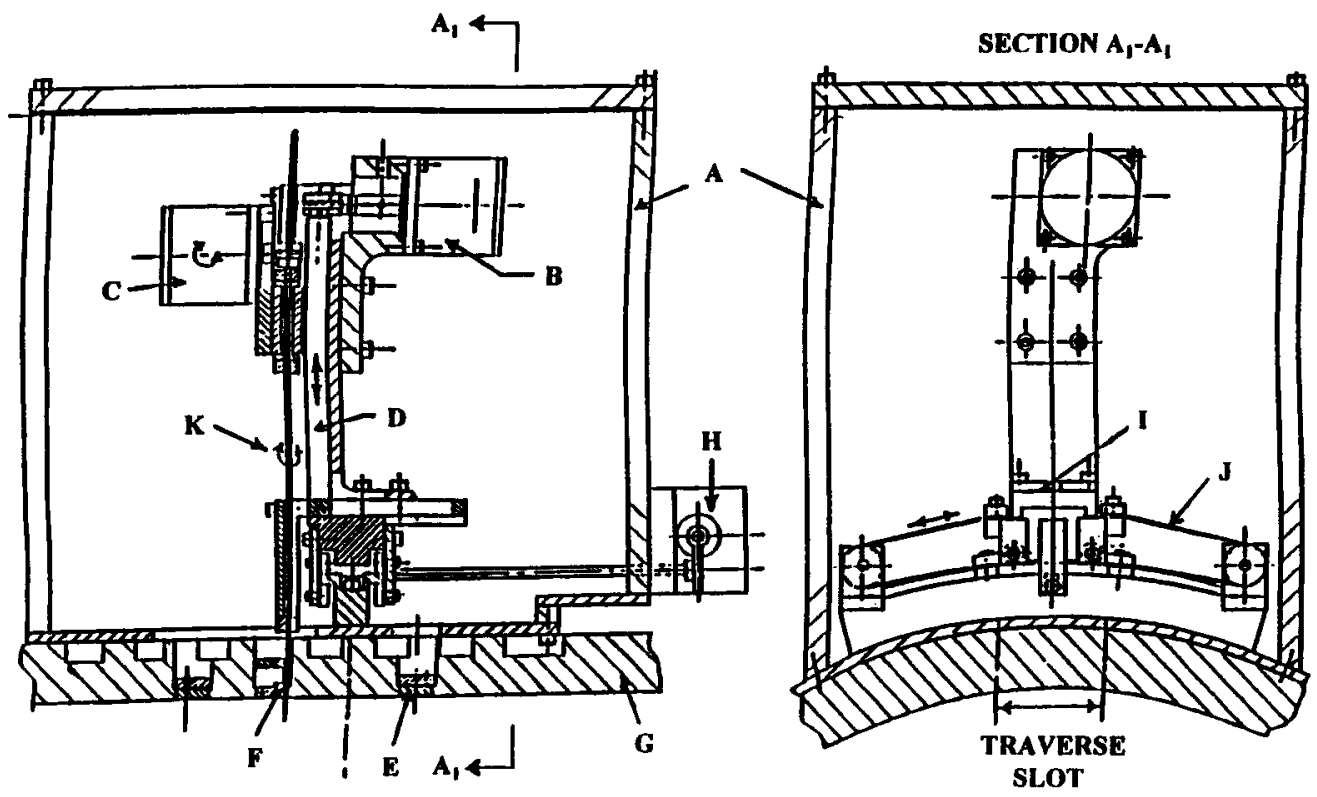

FIGURE 2 Schematic of area traverse mechanism.

area traverse can be stepped in very fine increments; thereby very high accuracy can be maintained. The minimum step size is $0.000115 \mathrm{~mm}$ in the radial direction and $0.00047^{\circ}$ in the tangential direction. The positioning is accurate to $\pm 0.05 \mathrm{~mm}$ in radial and tangential positioning and $\pm 0.0225^{\circ}$ in probe rotational positioning.

The data were acquired using a high-speed data acquisition system triggered by a once-per-rev pulse from an encoder mounted on the compressor shaft. A signal based upon the resolution of the rotor 2 blade passage ( 20 points per blade passage) obtained from a disc mounted on the same encoder is used to provide the clock frequency (approximately $130 \mathrm{kHz}$ for the second rotor) for the data acquisition system. At each location, approximately 2.78 seconds (250 rotor revolutions) of data was acquired. A 19 by 17 mesh (19 tangential nodes and 17 radial nodes) across one blade passage at stator 2 exit $(5.6 \%$ chord downstream of the stator trailing edge) with clustering in the endwall and the wake regions was employed to spatially resolve the flow field. At each measurement location, the 
slanted hot-film probe was rotated at four angular orientations, and data was recorded for all 250 rotor revolutions. All 250 revolutions of data were then averaged for each angular orientations, and the data was reduced to yield one ensemble-averaged revolution of deterministically unsteady total velocity, yaw, and pitch angles.

\section{DEVELOPMENT OF THE SLANTED HOT-FILM MEASUREMENT TECHNIQUE FOR THE MULTISTAGE ENVIRONMENT}

At the beginning of the present study, a slanted hot wire was used to measure the flow within the test compressor. The slanted wire usually lasted about one-half hour before failing under the unsteady aerodynamic load. After several attempts with the slanted hot wire, a TSI Model 1263-10 miniature platinum slanted hot-film probe (sensor dia. $=0.013 \mathrm{~mm}$ ) was tested. After several test runs, it was decided to use the slanted hot-film sensor since it never failed under the unsteady aerodynamic load within the test compressor. The frequency response of the slanted-film probe was initially in question as compared to that of the slanted hot wire. The frequency response of the slantedfilm sensor was optimized at $200 \mathrm{kHz}$ to a unit step function. As can be seen in the spectral plots presented later, the actual frequency response of the slanted-film sensor was sufficient to resolve ten harmonics of the compressor rotor 2 blade passing frequency of $6.5 \mathrm{kHz}$. Since the hot-film sensor was significantly larger in diameter than the hot wire, it was susceptible to flow induced vibrations as discussed below. These vibrations were eventually damped by application of Epoxy to the base of the sensor prongs, minimization of the diameter of the probe body and use of an anti-aliasing filter at one-half of the sampling frequency $(69 \mathrm{kHz})$. These items are discussed below.

\subsection{Flow Induced Vibration and Damping}

The trade off for the robustness of the slanted film sensor compared to the slanted hot wire was the tendency of the film sensor to undergo flow induced vibrations both in the calibrator jet and within the test compressor. In addition, the increased diameter of the hot-film probe caused it to be susceptible to accumulation of foreign debris. This issue will be discussed in a later section. Vibrations, not associated with shedding frequencies based on the diameter of the probe prongs or the probe body, were observed in both of the above mentioned flows and these were independent of the flow speed. The application of epoxy to the hot-film sensor prongs minimized the vibrations

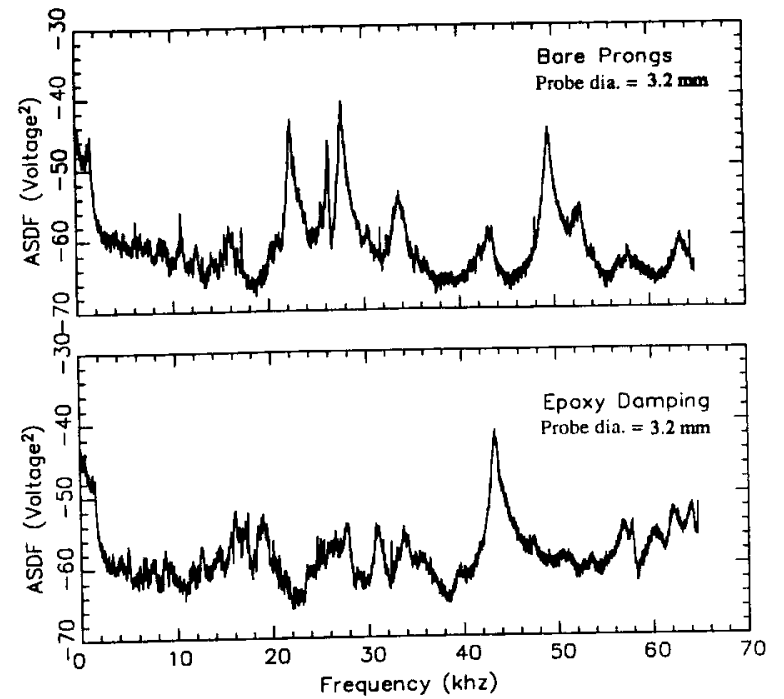

FIGURE 3 Film spectral energy distribution: bare prongs $v$ s. epoxy damping.

observed in the calibrator jet. In addition, the diameter of the body of the hot-film probe was minimized to further reduce vibrations within the test compressor. Finally, the use of an analog anti-aliasing low-pass filter stopped contamination of the measured hot-film spectrum from possible vibrations which were occurring above one half of the sampling frequency.

Figure 3 shows the auto spectral density function for the slanted hot-film sensor in the calibration jet at $85 \mathrm{~m} / \mathrm{s}$. The top spectrum is for a standard TSI slanted hot-film sensor with bare prongs, while the bottom spectrum is for the same probe with epoxy applied to the base of the prongs. The epoxy was applied to approximately one-half of the length of the prongs of the probe. The original length of the prongs was $6.0 \mathrm{~mm}$ or 1.89 times the probe diameter $(3.2 \mathrm{~mm})$. The effective length of the prongs was $2.0 \mathrm{~mm}$ or 0.63 times the probe diameter after application of the epoxy, which was smoothed aerodynamically into the body of the probe. The spectra of the probe with bare prongs shows large vibrations between 20 and $30 \mathrm{kHz}$ and near $50 \mathrm{kHz}$. After the application of epoxy to the prongs, the vibrations from 20 to $30 \mathrm{kHz}$ were damped. The vibration near $50 \mathrm{kHz}$, however, seemed to have moved closer to $44 \mathrm{kHz}$ but remained of the same order of magnitude. It is possible that this vibration was caused by the large probe body or aliasing from vibrations at higher frequencies.

Figure 4 shows the auto spectral density function for the slanted film sensor within the test compressor at $50 \%$ span downstream of stator 2 at the mid-passage. These spectra were obtained at the $100 \%$ speed, peak efficiency operating point of the compressor. All three spectra are from hot-film probes with epoxy damping applied to the base of the prongs as described above. The top spectra (Figure 4) is 


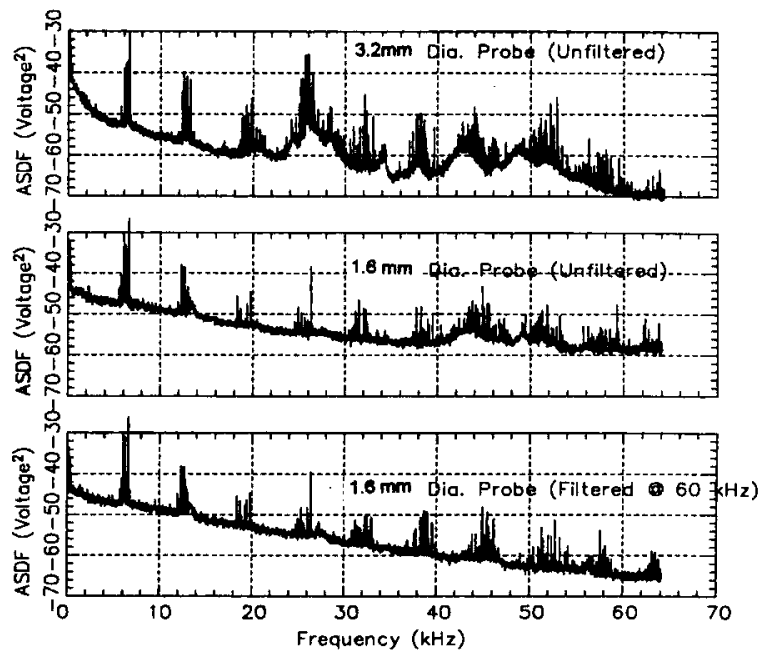

FIGURE 4 Hot-film spectral energy distribution 50\% span.

from the slanted hot-film sensor which had a larger body diameter of $3.2 \mathrm{~mm}$. Large flow induced vibrations can be seen from 24 to $28 \mathrm{kHz}$ and from 42 to $52 \mathrm{kHz}$ in the case of this probe. Some of the vibrations occur near or at blade passing frequency harmonics and may be related to or amplified by the unsteady flow within the machine.

The second spectra is from exactly the same probe sensor, but with a reduced body diameter of $1.6 \mathrm{~mm}$. Here the effective length of the prongs is 1.21 times the probe body diameter. In this case, the vibrations in the frequency range 24 to $28 \mathrm{kHz}$ are completely eliminated. The vibrations from 42 to $52 \mathrm{kHz}$ are also greatly reduced. A small amount of contamination of the spectra still exists between 42 to $52 \mathrm{kHz}$ and may be due to aliasing effects from vibrations at higher frequencies. The only difference between these two probes was the body diameter. Therefore, the increased body diameter was assumed to create larger flow disturbance within the compressor and hence the large amount of flow induced vibrations. These vibrations were seen to occur throughout the spectrum and seemed unrelated to the shedding frequency based on the diameter of the probe body or the prongs.

Finally, the third spectral plot of Figure 4 was taken with the probe of $1.6 \mathrm{~mm}$ diameter with a fourth order analog anti-aliasing filter at a cut-off frequency of $65 \mathrm{kHz}$. The small amount of contamination, which was still present in the second spectra from 42 to $52 \mathrm{kHz}$, has been eliminated. Therefore, this contamination was due to aliasing of energy (possible vibrational energy) past one half the data acquisition sampling rate of $65 \mathrm{kHz}$. Since the data acquisition sampling rate was a nominal $130 \mathrm{kHz}$, no unsteadiness past $65 \mathrm{kHz}$ could be resolved and the use of the low pass anti-aliasing filter served to insure a clean spectral energy content up to $65 \mathrm{kHz}$. A combination of epoxy applied to the prongs of the sensor, the use of the smallest diameter probe possible, and an anti-aliasing filter enabled accurate measurement of the spectral energy content in the measured flow field. Additional details, including spectral plots near the blade tip, can be found in Prato (1996).

\subsection{Correction for Flow Density Variation}

A miniature $(1.07 \mathrm{~mm}$ dia.) five-hole probe was traversed across the stator 2 exit passage to derive the quasi-steady state values. This probe is shown to be accurate, reliable, and has excellent repeatability (Prato, 1996). The development of the hot-film probe technique was motivated by the desire to measure not only the time-averaged velocities, but also to assess the deterministic and random unsteadiness present in such a harsh environment. Preliminary slanted hot-film measurements within the test compressor showed consistently higher voltages than those acquired during the calibration at the same temperature and velocity, based on the five-hole probe measurements in the test compressor. This trend was observed downstream of stator 2 and stator 3 of the compressor and was attributed to the increased flow density within the compressor compared to that at calibration. A similar phenomena has been reported by Wiech (1994) who saw decreased voltage levels between measurements within an axial turbine and his calibration facility at both the same flow velocity and temperature, due to decreased density.

In the present study, the velocities based on King's Law, without density corrections, resulted in measured velocities about $18 \%$ higher than the five-hole probe data reported in Prato (1996). An experiment within a pressurized tank showed that the voltage output of the anemometer at zero velocity was independent of the pressure and thus the density. Therefore King's Law for the calibration data could be written

$$
E_{c a l}^{2}=E_{o c a l}^{2}+B \rho_{c a l}^{0.5} V_{c a l}^{0.5}
$$

where $c a l$ refers to the measured values at calibration. All densities are normalized by a reference value (sea level).

Assuming a higher exponent on the density term, King's Law for the flow in the compressor was assumed to follow the relationship

$$
E_{m}^{2}=E_{o c a l}^{2}+B \rho_{m}^{n} V_{c a l}^{0.5}
$$

where $m$ refers to the measured values within the compressor. Based on the five-hole probe data at a few selected radial locations within the core regions of the flow field, the following correlation was derived for density variation (Prato, 1996)

$$
E_{m}^{2}=E_{o c a l}^{2}+B \rho_{m}^{0.7808} V_{c a l}^{0.5}
$$




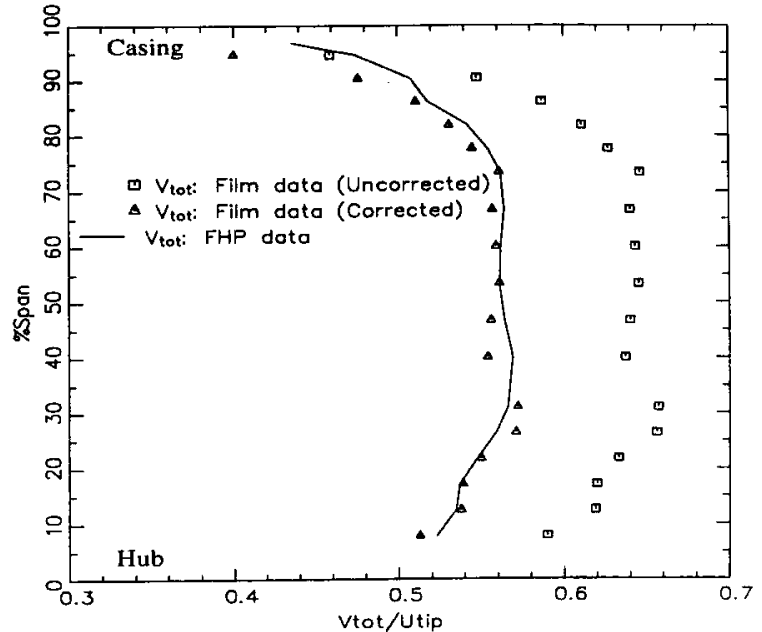

FIGURE 5 Density corrected and uncorrected hot-film data $v s$. five-hole probe data.

The constants $E_{o c a l}$ and $B$ were determined from the calibration data. Therefore, the heat transfer equations for the calibration data and for the compressor were manipulated to give the corrected voltage within the compressor, and this equation is given as

$$
E_{c a l}=\left(\left(E_{m}^{2}-E_{o c a l}^{2}\right) \sqrt{\rho_{c a l}} /\left(\rho_{m}\right)^{0.7808}+E_{o c a l}^{2}\right)^{1 / 2}
$$

This relationship showed excellent agreement between the five-hole probe data and the time-averaged hot-film data at the exit of stator 2 and stator 3 of the present test compressor, as shown in Figure 5. These comparisons demonstrate the validity of the derived equation for the flow within the present compressor and further validation is discussed later.

\subsection{Temperature Effects}

The hot-film anemometer output voltage is a linear function of the flow temperature at constant velocity (Bruun, 1995). Figure 6 shows the linear change in velocity at four different temperatures in the calibration tunnel. It is clear that the measured change in the velocity between the two sets of data $\left(T_{1}, T_{2}\right)$ is a linear function of the measured velocity at $T_{1}$. Hence the velocity at temperature $T_{n}$ (between $T_{1}$ and $T_{2}$ ) can be derived from the equation

$$
V_{n}=V_{1}+\left(V_{2}-V_{1}\right) \frac{\left(T_{n}-T_{1}\right)}{\left(T_{2}-T_{1}\right)}
$$

A temperature correction procedure was implemented in the data processing procedure. The hot-film probe was traversed in the compressor, noting the flow temperatures at constant intervals. The probe was then calibrated in the

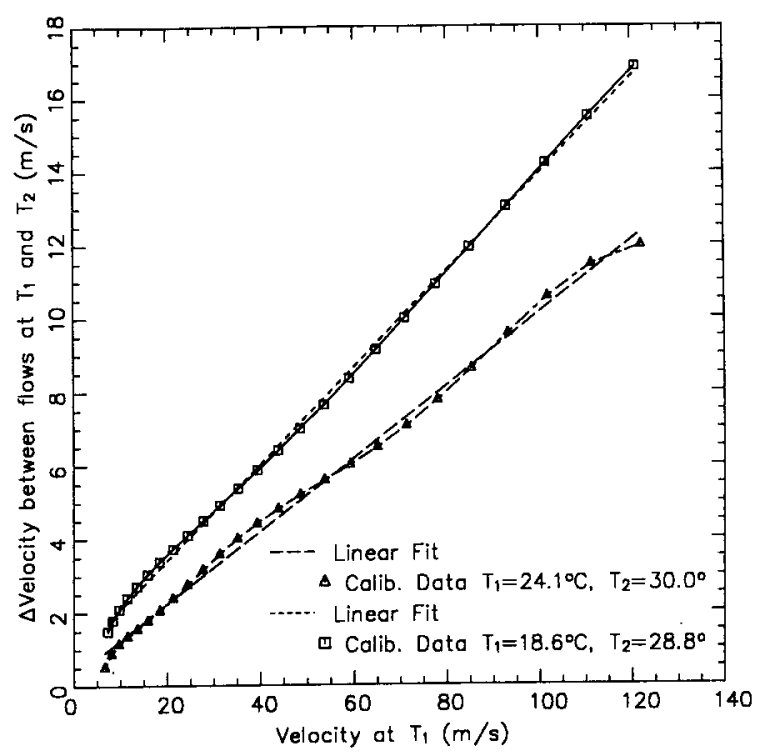

FIGURE 6 Linear change in velocity between curves at $T_{1}$ and $T_{2}$.

jet at the two extreme temperatures recorded in the compressor. The temperature variation during the test was within $\pm 6^{\circ}$. The interpolation method described above was used to correct the velocity data for the temperature variation.

\section{MEASUREMENT AND DATA PROCESSING PROCEDURE}

The slanted hot-film probe described earlier has been used to measure the ensemble-averaged three-dimensional unsteady velocity at the exit of the second stator of the Penn State Multistage Compressor at the $100 \%$ speed, peak efficiency operating point. The four angular rotation technique of Hanson et al. (1992) has been adopted for the present research. With this technique, 250 revolutions of data were taken at each of the four individual probe angular orientations. The data was ensemble averaged over 250 revolutions to yield one ensemble averaged revolution of data. This decomposition was carried out to determine the major sources and relative magnitudes of the periodic and aperiodic unsteadiness in a multistage environment. The overall measurement accuracy of the slanted hot-film sensor technique was determined both experimentally and analytically and is conservatively estimated as $\pm 2.5 \mathrm{~m} / \mathrm{s}$ or $2.5 \%$ in total velocity (at $100 \mathrm{~m} / \mathrm{s}$ ) and $\pm 1.0^{\circ}$ in both yaw and pitch angle measurement (Prato, 1996).

\subsection{Slanted Hot-film Calibration Procedure}

Before and after data acquisition, the slanted hot-film probe was calibrated for velocity and angular sensitivity at 


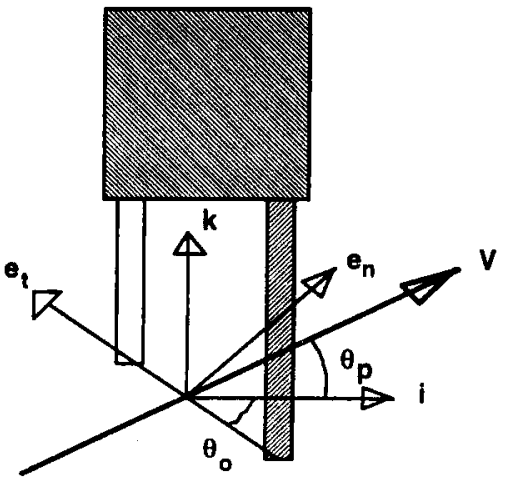

Side View

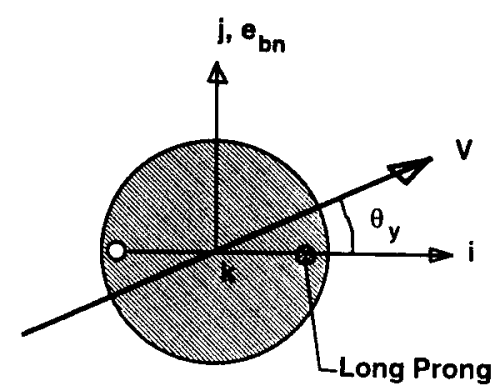

Bottom View

FIGURE 7 Hot-film probe geometry and coordinate system.

the temperature of the flow on the day of the test. A calibrator jet that incorporated continuously variable heating was used to set the frequency response and calibrate the slanted hot-film probe for velocity and temperature variation and angular sensitivity. The probe pitch range was $\pm 35^{\circ}$ with positioning accuracy of $0.1^{\circ}$. The probe yaw range was $180^{\circ}$ with position accuracy of $0.0225^{\circ}$.

The hot-film probe geometry and the coordinate system that are used to analyze the velocity relative to the probe is shown in Figure 7. The orientation of the coordinate system is fixed relative to the probe. The direction of vectors related to the sensing element relative to the probe body coordinate system is given by:

$$
\begin{aligned}
& e_{n}=\hat{i} \sin \theta_{o}+\hat{k} \cos \theta_{o} ; \\
& e_{t}=\hat{i}\left(-\cos \theta_{o}\right)+\hat{k} \sin \theta_{o} ; \quad e_{b n}=\hat{j}
\end{aligned}
$$

The pitch angle of the flow $\left(\theta_{p}\right)$ is measured between the velocity vector and a projection of the velocity vector onto the $\hat{i}-\hat{j}$ plane. The yaw angle of the flow $\left(\theta_{y}\right)$ is measured from the projection of the velocity vector onto the $\hat{i}-\hat{j}$ plane to the $\hat{i}$ vector. The velocity components are given by

$$
\begin{aligned}
& V_{z}=V \cos \theta_{p} \cos \theta_{y} \\
& V_{\theta}=V \cos \theta_{p} \sin \theta_{y}, V_{r}=V \sin \theta_{p}
\end{aligned}
$$

The velocity data from the calibration was curve fit with a high order polynomial, which can be written in the following form:

$$
V_{e f f}=\sum_{n=0}^{k} A_{n} \bullet E^{n}
$$

After calibrating for the velocity sensitivity, the second step in the calibration procedure was to calibrate for both the pitch and the yaw angle sensitivity. The measured voltage of the hot-film probe responds to an effective velocity, $V_{e f f}$, given by (Davis, 1991)

$$
V_{e f f}^{2}=h_{n}^{2} V_{n}^{2}+h_{b n}^{2} V_{b n}^{2}+k^{2} V_{t}^{2}
$$

Figure 8 shows the hot-film probe angular sensitivity calibration. The calibration curves are symmetric in the yaw plane and the curve fit is very good across the calibration map except at high positive and negative pitch angles. The accuracy of the curve fit in the pitch plane is very good from $-20.0^{\circ}$ to $20.0^{\circ}$. Outside this range, the accuracy of the curve fit in the pitch plane deteriorates. From knowledge of the five-hole probe data, the yaw and pitch angles, respectively, at the exit of stator 2 were expected to lie between $\pm 45^{\circ}$ and $\pm 20^{\circ}$ respectively. Therefore, over these ranges of yaw and pitch angles, the

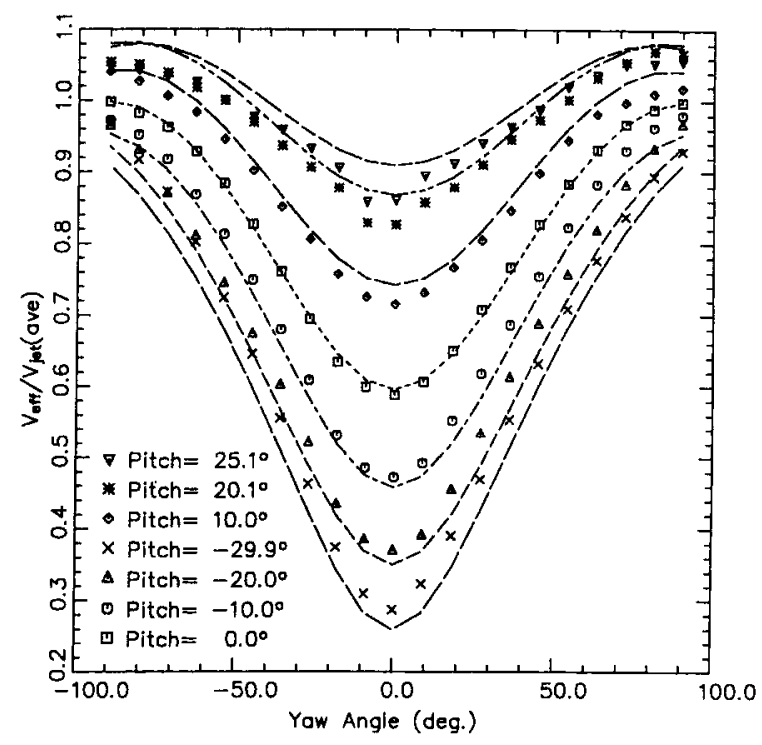

FIGURE 8 Hot-film angular sensitivity calibration 
curve fit of the angular sensitivity map shown in Figure 8 is quite accurate.

As can be seen in Figure 8, the calibration curves spread out near $\pm 90^{\circ}$ yaw angle. Several different slanted hot-film probes were tested to investigate the spreading of the calibration curves near $\pm 90^{\circ}$. For standard TSI slanted film probes, very little spreading of the calibration curves were observed. A standard TSI slanted film probe was modified by shortening the prongs in an attempt to dampen or reduce flow induced vibrations. This modified probe with short blunt prongs showed the same spreading of the calibration map characteristics as the present hot-film probe with epoxy applied to the base of the prongs (again to dampen flow induced vibrations). Simple tests were conducted by pitching the various probes at $\pm 90^{\circ}$ yaw angle to determine the cause of the spreading of the calibration map. For the modified short-pronged probe and the probe reported here with epoxy applied for vibration damping, the maximum cooling and thus the maximum anemometer output voltage occurred at the highest pitch angles. It was therefore concluded that the interference of the probe body in the case of the modified probe (with shortened prongs) and the epoxy in the case of the probe reported here caused flow blockage at lower pitch angles thereby reducing the voltage output compared to that at increased pitch angles. The spreading of the curves is accounted for in the calibration of the film sensor and it is expected to behave in the exact same manner within the test facility. Therefore, any aerodynamic flow disturbance caused by the presence of the epoxy on the probe prongs is taken into account in the calibration of the probe with the epoxy in place, and therefore, was not expected to affect the measured velocity within the test compressor.

\subsection{Error Due to Misalignment and Foreign Debris}

Probe angular misalignment and accumulation of foreign debris results in asymmetry in the hot-film calibration. Initial misalignment in the yaw angle of the film sensor caused asymmetry in the yaw plane of the pitch-yaw calibration map of the probe. Cumulative errors in the alignment in the yaw angle caused by gear lash (due to changes in angular directional movement) resulted in asymmetry in the yaw plane of the calibration space of the slanted hot-film probe. Accurate alignment of the yaw angle was achieved by iteration until the effective velocity, $V_{\text {eff }}$ at $+45^{\circ}$ was equal to that at $-45^{\circ}$. This proved to be the optimal way of aligning the hot-film sensor in the yaw plane. The cumulative errors in the yaw angle alignment due to gear lash associated with rotational direction changes was eliminated by preserving a constant direction of hot-film sensor angular rotation about its own axis.
A slanted-film sensor can be up to 25 times (or more) the diameter of a typical hot-wire sensor. Therefore, it is more suseptible to accumulation of foreign debris. Significant foreign debris accumulation on the film sensor was due to the impingement of the flow on the hot-film sensor during the time the operating point of the test compressor was being set. The debris accumulation also caused asymmetry in the yaw plane of the calibration map of the hot-film probe. This problem was avoided by hiding the film sensor behind the stator blade and placing the sensor at a "cover" angle in which the long prong and the sensor was aligned in the mean flow direction to block impingement of the flow and the resulting accumulation of foreign debris on the hot-film sensor. Once the operating point of the test compressor was set, the slanted hot-film probe was rotated about its axis and data was acquired at each of the four angular orientations chosen, based on the mean yaw angle at each radii. Between each tangential probe movement, the hot-film sensor was placed at a "cover" angle equal to the "passage-averaged" flow angle based on the five-hole probe data.

Figure 9 shows the effect of the accumulation of foreign debris on the slanted hot-film sensor. The removal of foreign debris can be achieved by gently brushing the sensor with a miniature camel hair brush dipped in Methyl Alcohol (or Methanol) and then drying the sensor with a clean stream of air from a miniature jet with a filter at the inlet. It is recommended that the slanted hotfilm sensor be hidden while the operating point of the test machine is set to reduce the possibility of potential dirt or other foreign debris accumulation on the sensor. For the present study, the film sensor was placed behind the stator blade at a "cover" angle in which the sensor was aligned parallel with the passage-averaged flow angle at radii.

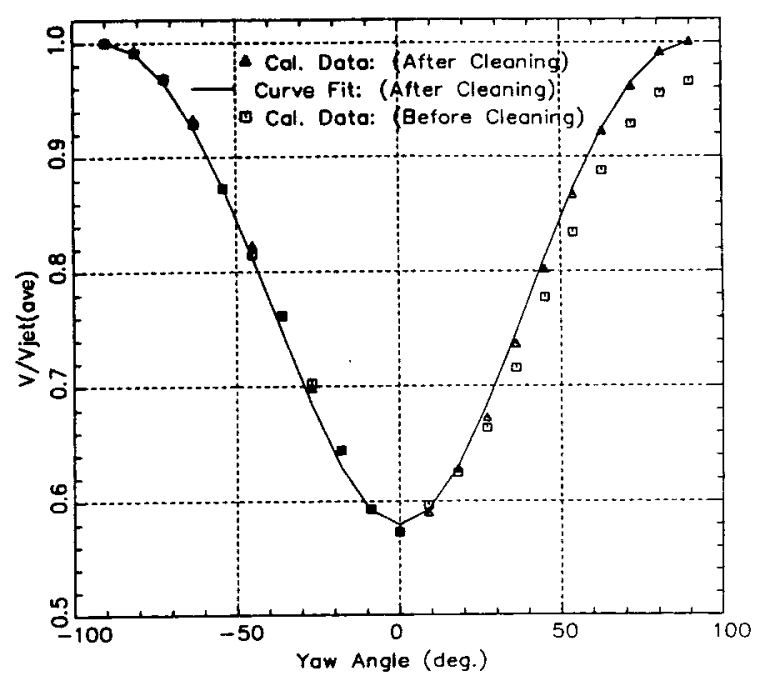

FIGURE 9 Effect of foreign debris deposit on film sensor calibration. 


\subsection{Data Acquisition and Processing Procedures}

Before data acquisition in the multistage compressor, the probe traverse mechanism was mounted directly on the calibrator. All the velocity and angular sensitivity calibration curves were generated using this procedure. The area traverse mechanism was then placed in the area traverse chamber of the multistage compressor and mounted on the tangential traverse (Figure 2). The angular starting position of the traverse was set by the use of a microswitch mounted in line with the tangential traverse.

In order to obtain the three components of periodically unsteady velocity, data was acquired at four different film orientations as discussed in Hanson et al. (1992). To acquire data at different wire orientations, the probe was rotated about its axis, which is equivalent to a rotation around the $z$-axis of the probe coordinate system. Figure 10 shows the various orientations used to acquire the unsteady velocity data. The view is from above and sighting down the axis of the probe (z-axis). The orientation angle $\left(\varphi_{i}\right)$ was recorded and measured relative to the minimum anemometer output voltage at each measured location, referred to as the null position. The effective velocity at each wire position is given by:

$$
V_{e f f 1}^{2}=h_{n}^{2}\left(V \cdot \hat{e}_{n i}\right)^{2}+h_{b n}^{2}\left(V \cdot \hat{e}_{b n i}\right)^{2}+k^{2}\left(V \cdot \hat{e}_{t i}\right)^{2}
$$

where $\mathrm{i}$ is the position number. For each angular hot-film position there is one unique equation based on Eq. [10]. Since there are three unknowns $\left(V, \theta_{y}\right.$ and $\left.\theta_{p}\right)$, three independent equations would be necessary to solve the system. A minimization of error scheme was used to obtain the solution, which utilized four angular hot-film

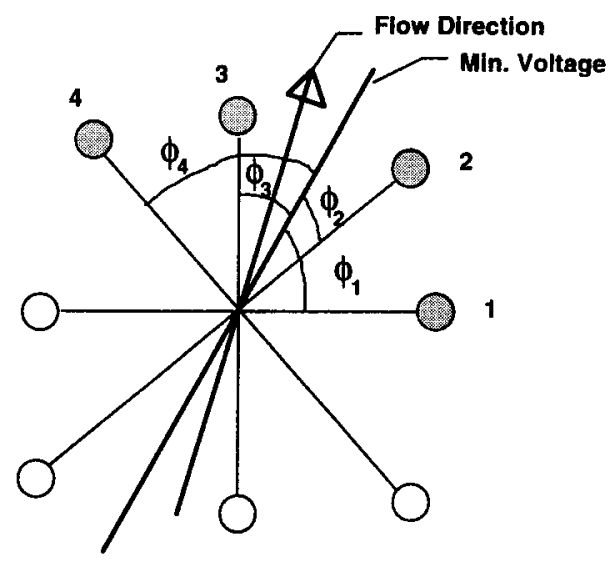

Indicates Short Prong

Indicates Long Prong

FIGURE 10 Various hot-film orientations to acquire unsteady velocity. orientations. The magnitude of the measured velocity can be written in terms of the unit vectors in the hot-film plane, the transformation matrix from the null position to the $i$ th measurement location, and the effective velocity at the $i$ th measurement location. The transformation matrix is given by (Hanson et al., 1992):

$$
|V|=\frac{V_{e f f 1}}{\sqrt{h_{n}^{2}\left(e_{n}^{T} A_{i} e^{2}\right)+h_{b n}^{2}\left(e_{b n}^{T} A_{i} e^{2}\right)+k^{2}\left(e_{t}^{T} A_{i} e^{2}\right)}}
$$

where the unit vector $e$ is in the direction of the velocity and is written with respect to the probe body co-ordinate system at the null position (Figure 7) and $e$ and $A_{i}$ are given by

$$
e=\left[\begin{array}{c}
\cos \theta_{p} \cos \theta_{y} \\
\cos \theta_{p} \sin \theta_{y} \\
\sin \theta_{p}
\end{array}\right] \quad A_{i}=\left[\begin{array}{ccc}
\cos \phi_{i} & -\sin \phi_{i} & 0 \\
\sin \phi_{i} & \cos \phi_{i} & 0 \\
0 & 0 & 1
\end{array}\right]
$$

The unit vectors in the hot-film sensor coordinate plane $\left(e_{n}\right.$, $e_{b n}$, and $e_{t}$ ) are given by (Figure 7),

$$
e_{n}=\left[\begin{array}{c}
\sin \theta_{o} \\
0 \\
\cos \theta_{o}
\end{array}\right], e_{b n}=\left[\begin{array}{l}
0 \\
1 \\
0
\end{array}\right], e_{t}=\left[\begin{array}{c}
-\cos \theta_{o} \\
0 \\
\sin \theta_{o}
\end{array}\right]
$$

Hence, the product $e_{n}^{T} A_{i} e$ is the magnitude of the normal component of the unit vector in the direction of the velocity written with respect to the sensing element coordinate system at the $i$ th measurement orientation. Once the magnitude of the total velocity is known, the velocity components can be calculated from a knowledge of the hot-film sensor orientation and its relationship to the machine coordinate system. These velocity components can then be resolved into periodic and aperiodic velocity components and the time-averaged normal stresses using the ensembleaveraging technique, discussed below.

\section{UNSTEADY VELOCITY FIELD DECOMPOSITION PROCEDURE}

Based on the terminology of Suder et al. (1987), an instantaneous quantity (velocity and angle) $P_{i j k}$ can be decomposed into:

$$
P_{i j k}=\bar{P}+\left(\hat{P}_{j}\right)_{R A P}+\left(\tilde{P}_{k}\right)_{B P}+\left(\hat{P}_{j k}\right)_{B A P}+P_{U R}^{\prime}
$$

where the subscripts $i, j$, and $k$ represent indices in the ensemble averaging technique $(i$ indicates the index of revolution, $j$ the index of the blade in the row, and $k$ the index of the point in the blade passage), $\bar{P}$ is the time average, $\left(\hat{P}_{j}\right)_{R A P}$ is the revolution aperiodic component 
(passage-to-passage average), $\left(\tilde{P}_{k}\right)_{B P}$ is the blade periodic component, $\left(\hat{P}_{j k}\right)_{B A P}$ is the blade aperiodic component, and $P_{U R}^{\prime}$ is the unresolved component (unresolved fluctuations). Since the data were ensemble averaged over 250 revolutions to achieve an average unsteady revolution of data at each slanted hot-film angular orientation, the unresolved velocity component is averaged out. The combination of $\left(\tilde{P}_{k}\right)_{B P}$ and $\left(\hat{P}_{j k}\right)_{B A P}$ is the total periodic fluctuating component of the instantaneous quantity. The timeaveraged quantity, which is the same for all blades in a blade row, describes the steady state velocity flow field. The revolution aperiodic velocity component (passage-to-passage average) arises from differing rotor (stator) blade counts in successive stages. The temporally periodic fluctuating component arises due to relative motion between blade rows. The blade periodic component is equivalent to an average blade passage and is assumed to be constant for all blade passages in that blade row. The time average of the instantaneous quantity is given by:

$$
\bar{P}=\frac{1}{N_{r e v} x N_{b} x N_{p b}} \sum_{i=1}^{N_{r e v}} \sum_{j=1}^{N_{b}} \sum_{k=1}^{N_{p b}} P_{i j k}
$$

where, $N_{r e v}$ is the number of revolutions, $N_{b}$ the number of blades per revolution (number of blades on the rotor in question) and $N_{p b}$ the number of points per blade (resolution of the rotor blade passage). The ensemble average of the data for one rotor revolution is calculated by the equation

$$
\tilde{P}_{E N S}=\frac{1}{N_{r e v}} \sum_{i=1}^{N_{r e v}} P_{i j k}
$$

The full revolution of ensemble-averaged velocity data is decomposed into a revolution aperiodic component $\left(\left(\hat{P}_{j}\right)_{R A P}\right)$, blade periodic component $\left(\tilde{P}_{k}\right)_{B P}$ and the blade aperiodic component $\left(\hat{P}_{j k}\right)_{B A P}$. The revolution aperiodic component is given by:

$$
\left(\hat{P}_{j}\right)_{R A P}=\frac{1}{N_{p b}} \sum_{k=1}^{N_{p b}}\left[\tilde{P}_{E N S}-\bar{P}\right]
$$

The blade periodic component is given by:

$$
\left(\tilde{P}_{k}\right)_{B P}=\frac{1}{N_{b}} \sum_{j=1}^{N_{b}}\left[\tilde{P}_{E N S}-\left(\hat{P}_{j}\right)_{R A P}-\bar{P}\right]
$$

and the blade aperiodic component is given by:

$$
\left(\hat{P}_{j k}\right)_{B A P}=\left\lfloor\tilde{P}_{E N S}-\left(\hat{P}_{j}\right)_{R A P}-\bar{P}-\left(\tilde{P}_{k}\right)_{B P}\right\rfloor
$$

\section{TYPICAL RESULTS AND DISCUSSION}

It is beyond the scope of the present paper to present and interpret the steady and unsteady flow data acquired in the multistage compressor. Comprehensive data, analysis and interpretation are presented in Prato et al. (2001) and Suryavamshi et al. (2001). The data confirming the validity of the proposed measurement technique is presented in this paper, followed by representative data on the complexity of the multistage compressor flow field. Figure 11a shows the comparison of the time-averaged slanted film total velocity with the five-hole probe data at $5.6 \%$ chord downstream of the second stator of the test compressor. Very good agreement is obtained between the two measurement techniques in terms of the wake velocity defect and the wake width. Repeatability of the measurement technique is

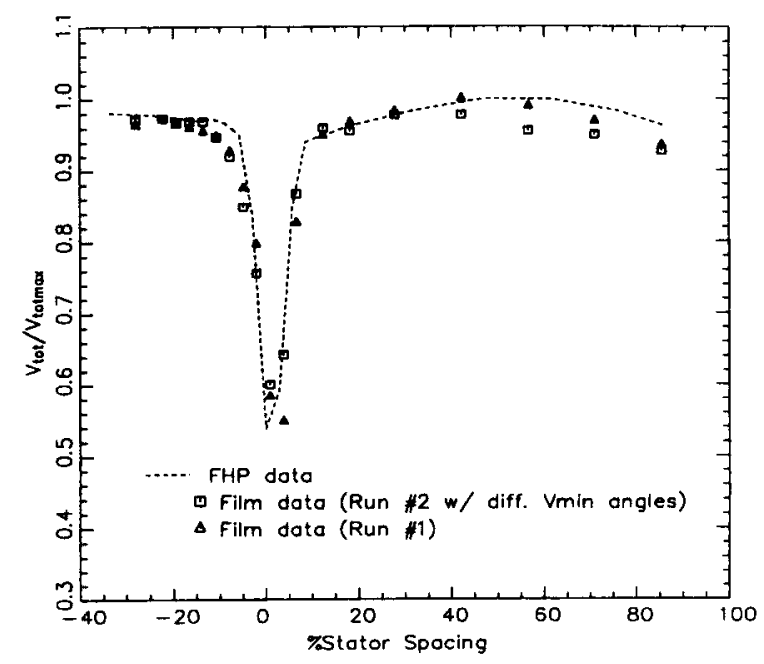

FIGURE 11a Repeatability of time-averaged total velocity.

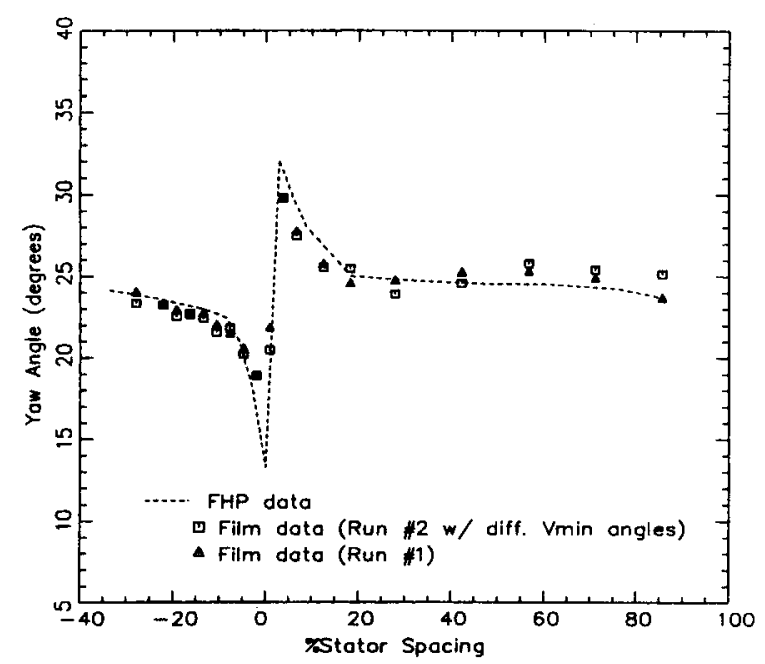

FIGURE 11b Repeatability of time-averaged total yaw angle. 
also demonstrated in this figure. Run number two in Figure 11a was obtained by using different film orientation angles than in Run number one. Therefore, this demonstrates that the orientation angles do not affect the results as long as the flow angles are within the calibrated space of the hot-film probe. A small discrepancy in the data between the two runs in the core region could be due to slight differences in the operating point of the compressor when the two tests were conducted. Figure $11 \mathrm{~b}$ shows the comparison of the time-averaged film yaw angle with the five-hole probe data. In the core region, the two measurement techniques are in agreement to about a degree. A discrepancy exists within the wake as the film sensor does not exhibit the same level of over- and under-turning on the suction and pressure sides of the wake, respectively. The sensing length of the five-hole probe is $1.07 \mathrm{~mm}$, whereas the sensing length of the hot-film sensor is only $0.3 \mathrm{~mm}$ and therefore has better spatial resolution. The repeatability of the film data between runs one and two shows agreement everywhere to within one degree in the core and within the wake region of the stator 2 exit flow. Figure 11c shows the comparison of the time-averaged film pitch angle with that of the five-hole probe. In the core region, the two measurement techniques agrees quite well. The radially inward flow within the wake is captured equally by both techniques. On the suction side of the stator wake, the film sensor measures outward flow; but, the five-hole probe does not. It is possible that a vortical fluid motion exists at this trailing edge location, but the larger size of the five-hole probe has caused the decay or interference of this flow structure. Some scatter exists between the two different film runs, even though the same trend is repeated. As discussed earlier, the hot-film data is again believed to be more accurate than the five-hole probe data.

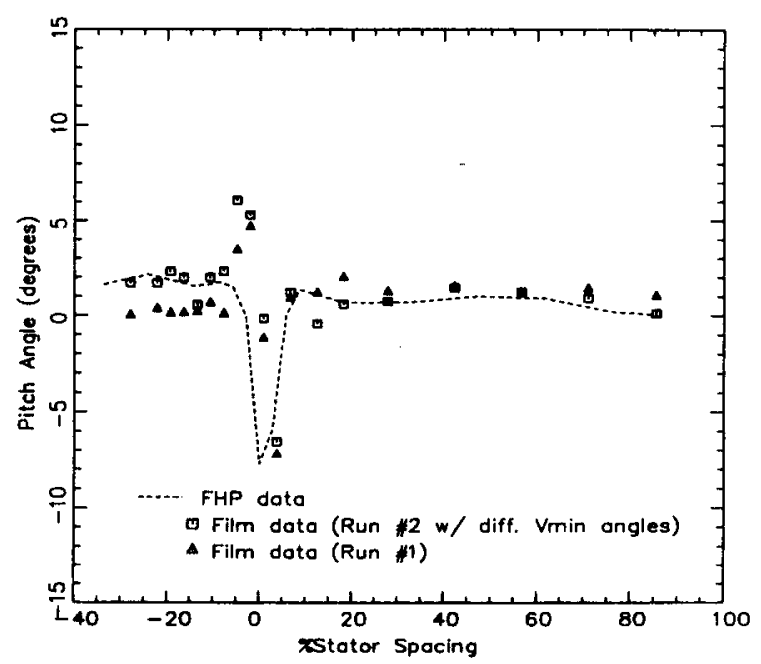

FIGURE 11c Repeatability of time-averaged pitch angle.

\subsection{Contours of Total Velocity, Yaw and Pitch Angles}

The unsteady hot-film data were time averaged and is discussed in this section. The time average total velocity contours compare well with data obtained with the fivehole probe (Prato, 1996). For the contour plots presented in this section, the hub rotation is from right to left as indicated by the arrow in the plots. The casing and hub wall are indicated at $0 \%$ and $100 \%$ span, respectively. The hot-film probe traverses were conducted from $7.86 \%$ to $94.71 \%$ span at $5.6 \%$ chord downstream of the second stator of the test compressor. The trailing edge of the stator 2 blade is also indicated in the plots as well as the pressure and suction sides of the stator blade.

Figure 12a shows the contour of the time-averaged total velocity field. The presence of the stator blade wakes, the hub and casing endwall boundary layers, and the thickening of the stator wakes near the suction surface casing corner is clearly seen. The stator wake thickness is minimal from $40 \%$ to $60 \%$ span where the flow is essentially two dimensional (with low radial flows). Near the rotating hub endwall, the stator wake width has increased due to the scraping of the low momentum hub boundary layer fluid by the stator blade. The stator blade clearance is about $1.5 \%$ of the span whereas the hub endwall boundary layer extends to nearly $15 \%$ span. Since the hub endwall flow is moving slower than the fluid in the core region, the lower momentum endwall fluid is scraped by the pressure side of the stator blade due to hub rotation. This results in downstream vortical fluid motion as observed by Prato (1996).

Considering Figure 12a, the boundary layer region near the casing extends from the casing to nearly $70 \%$ span. This larger region of low momentum fluid (compared to that at the hub endwall) is due to the losses generated through previous rows of the compressor. The flow in the

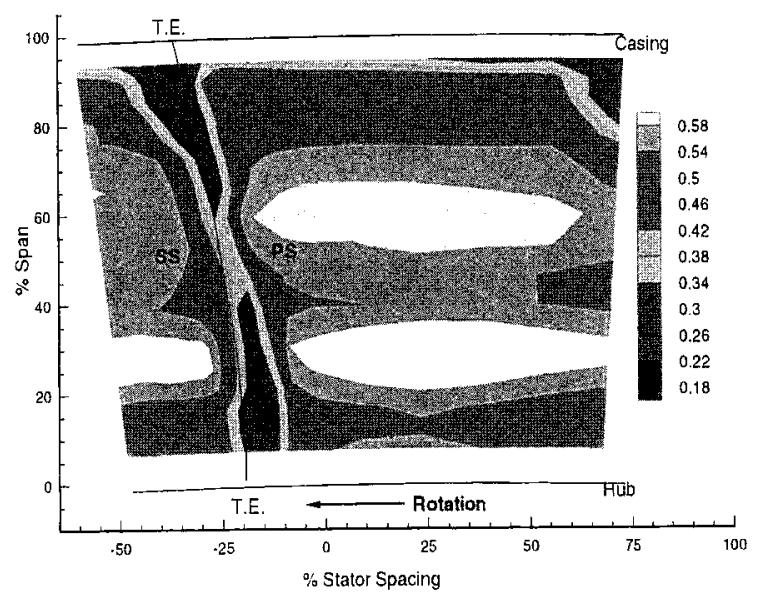

FIGURE 12a Contour of time averaged total velocity $\overline{V_{t o t}} / U_{t i p}$ (See Colour Plate at back of issue.). 
corner region on the suction side of the stator blade represents a major, if not the most significant, contribution to the flow unsteadiness to the downstream rotor. This is the region where the maximum interaction between the stator suction side corner flow and the rotor leakage flow occurs, hence this region is a major source of loss and off-design conditions for the inter-stage design. The cumulative effects of preceding blade rows results in a viscous layer region which extends to nearly $30 \%$ of the span as opposed to that at the hub endwall which extends to only $15 \%$ of the span.

Figure $12 \mathrm{~b}$ shows the time-averaged yaw angle contour at $5.6 \%$ chord downstream of the stator exit plane derived from the slanted hot-film data. In the core region, the yaw angle increases from about $17^{\circ}$ to about $30^{\circ}$. Near the casing (at midpitch), the flow is overturned due to the secondary flow from the pressure to the suction side of the stator blade, which is consistent with trends predicted by secondary flow theories (Lakshminarayana,

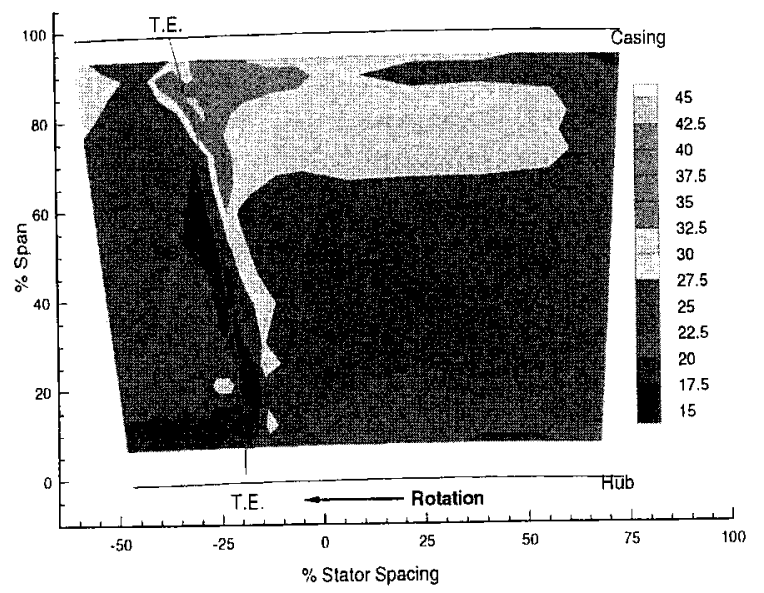

FIGURE 12b Contour of time averaged yaw angle $\bar{\alpha}$ (degree) (See Colour Plate at back of issue.).

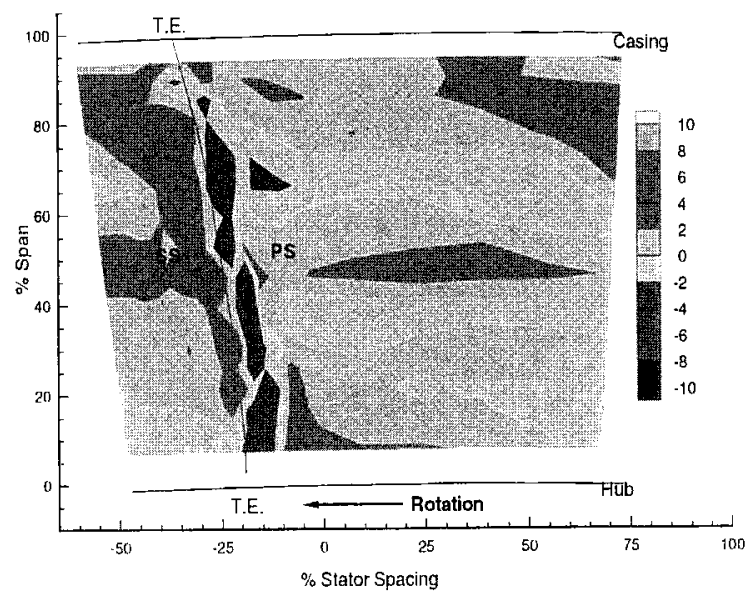

FIGURE 12c Contour of time averaged pitch angle, $\bar{\beta}$ (degrees) (See Colour Plate at back of issue.).
1996). The flow is overturned on the suction side and underturned on the pressure side of the stator blade. Secondary flow induces overturning near the casing across the entire passage. Its dominant effect is near the suction surface of the casing. Therefore, the wake flow and secondary flow have a cumulative effect in overturning the flow near the suction surface while having an opposing effect near the pressure surface. Maximum overturning and under-turning inside the wake is observed near the outer radii. The variation across the wake is minimum near the mid-span, moderate near the hub and maximum near the tip.

Figure $12 \mathrm{c}$ shows the contour of time-averaged pitch angle at $5.6 \%$ chord downstream of the stator 2 exit plane. Within the core region, the pitch angle is quite small ranging from $-2^{\circ}$ to $2^{\circ}$ which is near the uncertainty band of the measurement technique. Within the stator wake, the flow is radially inward on the pressure side of the wake due to the imbalance between the radial pressure gradient and the decreased centrifugal force acting on the fluid particles due to the decreased tangential velocity of the fluid particles within the wake. On the suction side of the stator blade wake, significant radial outward flow was measured by the slanted film sensor. The radially outward flow indicates the presence of a trailing edge vortex with its axis aligned in the downstream direction.

It was observed from the instantaneous effective velocity that the unresolved unsteadiness was as high as $25 \%$ near the suction-casing corner, and periodic unsteadiness as high as $17 \%$ was observed in the stator wake.

\section{CONCLUDING REMARKS}

The slanted hot-film technique has been successfully modified and adopted for flow measurement in a complex, hostile environment and narrow passages in a multistage turbomachinery. The probe diameter and prong length were optimized to reduce probe vibration and increase the frequency response. The time-averaged flow data acquired from the hot-film probe has been successfully validated against the data from a miniature five-hole probe. The total velocity, yaw and pitch angles agree very well with the fivehole probe data. Furthermore, sources of errors (angularity and foreign debris) have been identified. A successful attempt has been made to develop the hot-wire equations and calibration technique that include the compressibility effect. The standard equations, without modification, results in a large error (as much as $20 \%$ in this case) in derived velocities. Future attempts should be directed towards achieving a successful universal correlation for compressibility effects for such flows.

The slanted hot film is a powerful technique for measuring the time average, blade and revolution periodic, 
aperiodic, and unresolved (and random) components in a multistage environment. Such flows are not accessible for measurement by any other technique, including laser doppler velocimeter. The data provides valuable information for flow modelers and for the validation of computational procedures.

The contour plot of axial velocity reveals that the wake width is about $20 \%$ of the blade spacing away from the endwalls at the peak $\eta$ efficiency operating condition. A trailing edge vortex system with its axis aligned in the downstream direction is believed to be the source of the radially inward and outward flow on either side of the stator blade near the wake. The small sensing area of the slanted film sensor is able to capture small scale flow structures. Near the casing (at midpitch), the flow is overturned due to the secondary flow from the pressure to the suction side of the stator blade. Near the hub, the expected secondary flow very close to the hub endwall is not observed due to the rotation of the hub endwall and the entrainment of the hub boundary layer fluid across the passage in the direction opposite of that of the secondary flow.

\section{Acknowledgments}

This project was supported by the DOE's METC through the South Carolina Research and Development Center (subcontract 95-01-SRO36), NASA Lewis Research Center (NAG3-1222), and the Allison Engine Company. Helpful suggestions by Dr. A. Strazisar, Dr. Bruce Reichert and Mr. Fred Newman of NASA Lewis Research Center and Drs. R. Fagan and E. Hall of Allison Engine Company are gratefully acknowledged. The authors also wish to acknowledge United Technologies Research Center (UTRC)/Pratt \& Whitney Aircraft Division of United Technologies Corporation for donating the multistage compressor facility to Penn State.

\section{NOMENCLATURE}

A

$A S D F$

$B, b$

$e_{n}, e_{b n}, e_{t}$

E

$L_{n}, h_{b n}, k$
n
$\mathrm{N}$

$\bar{P}$

Calibration constant, transformation matrix

Auto spectral density function Calibration constants Unit vectors in slanted film sensor coordinate system in the normal, binormal, and tangential directions, (Figure 7)

Anemometer output voltage

Zero flow anemometer output

Normal, binormal, and tangential film cooling coefficients, respectively Eq. [9]
$I, j, k$

$m$

$P_{\mathrm{ijk}}, P_{\mathrm{ijk}}^{\prime}$

$\left(\hat{P}_{j}\right)_{R A P},\left(\tilde{P}_{k}\right)_{B P},\left(\hat{P}_{j k}\right)_{B A P}$

$P S, S S$

$R$

RMS

$T$

$U_{t}$

$V_{n}, V_{b n}, V_{t}$

$V_{\text {eff }}$

$V_{\text {eff } 1}$

$V_{t o t}$

$V_{\text {zin }}, V_{z}$ (inlet)

$\theta_{0}$

$\theta_{p}, \theta_{y}$

$\varphi_{i}$

$\alpha$

$\beta$

Subscripts

Unit vectors in the slanted hotfilm probe coordinate system (Figure 7)

Calibration constant

Shaft Rotational speed in RPM Instantaneous and unresolved quantity $P$

Time-average value of quantity $P$ Revolution aperiodic, blade periodic and blade aperiodic component of quantity $P$ (Eqs. [14]-[19])

Pressure and suction side

Radius in \% span, tip radius

Root mean square value

Transpose of a matrix, time period

Rotor 2 blade tip speed

Absolute total velocity

Velocity components in the hotfilm sensor coordinate system in the normal, binormal, and tangential directions, respectively

(Eq. [9] and Figure 7)

Effective cooling velocity

Effective cooling velocity at film orientation 1

Total velocity

Average inlet axial velocity

Slanted hot-film sensor inclination angle $=45^{\circ}$ (Figure 7)

Pitch and yaw in slanted film probe coordinate system (Figure 7)

Angular orientations of the slanted film sensor $(i=1-4)$

yaw angle in degree pitch (or radial) angle in degrees Fluid (air) density normalized by sea-level values

BAP, BP

$b n$

cal

ENS

jet

$m$

$n$

RAP, RP

$r, \theta, z$
Blade aperiodic and periodic (Eqs. [18], [19])

Binomal direction

Calibration

Ensemble average

Calibration jet

Measured quantity

Normal direction

Revolution aperiodic and periodic Eq. [17]

radial, tangential, and axial components 
totper, totun

$U R$

Superscripts

$\sim$

$-$
Total periodic and unresolved unsteadiness

Unresolved

Periodically fluctuating component

Unresolved fluctuating component

Blade-to-blade passage average/ time average

\section{REFERENCES}

Bruun, H. H. (1995) Hot-wire Anemometry, Oxford Science Publications. Cherrett, M. A. and Bryce, J. D. (1992) "Unsteady Viscous Flow in a High Speed Core Compressor", ASME Journal of Turbomachinery, 114, 287-294.

Davis, D. O. (1991) "Experimental Investigation of Turbulent Flow Through a Circular-to-Rectangular Transition Duct", $P h$. D. Thesis, University of Washington (also as NASA TM 105210 ).

Hanson, K. A. et al. (1992) "Three-Dimensional Unsteady Hot-wire Anemometry Technique for the NASA Low Speed Centrifugal Compressor", NASA TM 105339.

Inoue, M., Kuroumaru, M. and Fukuhara, M. (1986) "Behavior of Tip Leakage Flow Behind an Axial Flow Compressor", Journal of Engineering Power, 108(1), 7-14.

Lakshminarayana, B. (1981) "Techniques for Aerodynamics and Turbulence Measurements in Turbomachinery Rotors", ASME Journal of Engineering Power, 108, 374-379.

Lakshminarayana, B. (1996) Fluid Dynamics and Heat Transfer of Turbomachinery, John Wiley Inc.

Lakshminarayana, B. et al. (1994) "Experimental Investigation of the Flow Field in a Multistage Axial Flow Compressor", ASME Paper 94-GT-455

Prato, J. P. (1996) "Three Dimensional Steady and Unsteady Flow Field Downstream of an Embedded Stator of a Multistage Axial Flow Compressor', Ph. D. Thesis, The Pennsylvania State University.

Prato, J. P. et al. (2001) "Three dimensional flow field downstream of an embedded stator in a multistage axial Flow compressor". Part I Steady and Unsteady Flow Field. Ins. Mech. Engs., J. Power and Energy, Vol. 215 (To be published).

Stauter, R. C. (1992) "Measurement of the Three-Dimensional Tip Region Flowfield in an Axial Compressor", ASME Paper 92-GT-211.

Suder, K. L. et al. (1987) "Measurements of the Unsteady Flow Field Within the Stator Row of a Transonic Axial Flow Fan, Part I: Measurement and Analysis Technique", ASME Paper No. 87-GT-226.

Suryavamshi, N. et al. (1997) "Unsteady Total Pressure Field Downstream of an Embedded Stator in a Multistage Axial Flow Compressor", J. Fluids Engineering, 119, Dec., 1997, 985-994.

Suryavamshi, N. et al. (2001) "Three dimensional flow field downstream of an embedded stator in a multistage compressor", Part II Deterministic stress and Heat flux distribution and average passage equation. Ins. Mech. Engs., J. Power and Energy, Vol. 215 (To be published).

Wiech, D. (1994) "Correction Procedure for Hot-Film Calibration for Measurements in Compressors and Turbines" (in German), MTU Munchen Report, MTUM-N94EEM-0002. 

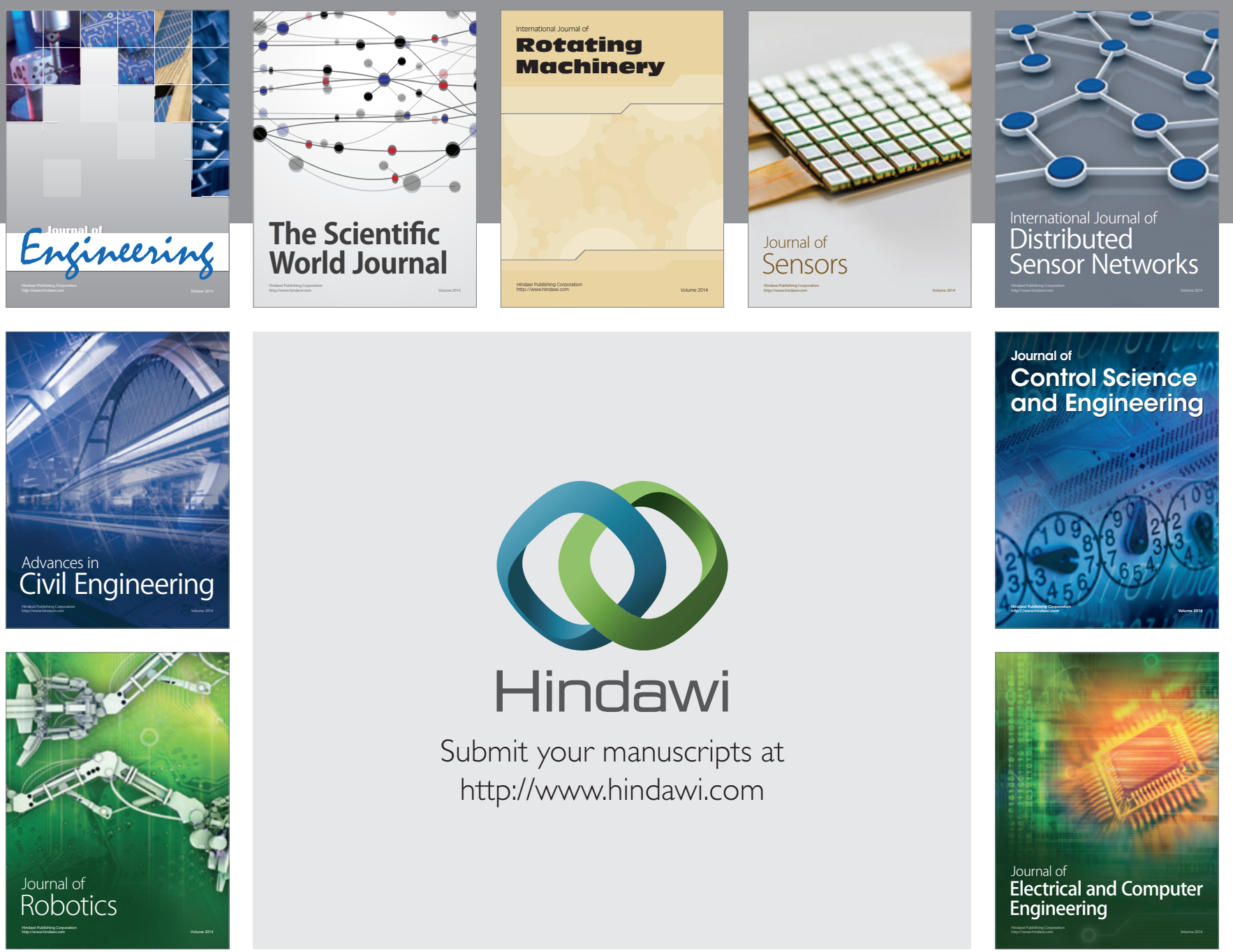

Submit your manuscripts at

http://www.hindawi.com
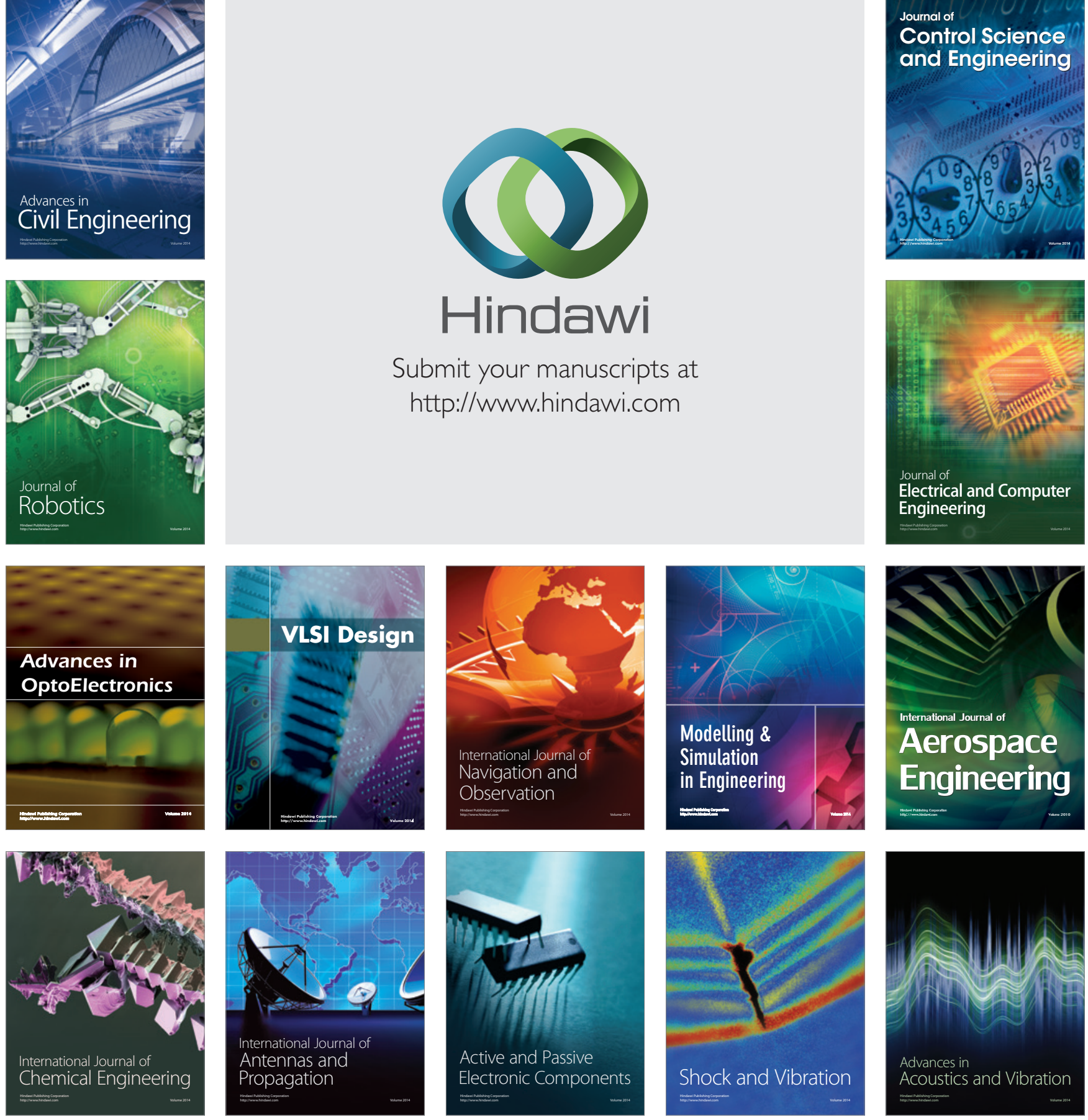